\title{
Wide Angular Aperture Circularly Polarized Low-Profile EBG Antenna
}

\author{
Moustapha Salah Toubet, ${ }^{1}$ Ahmad Elsayed Ahmad, ${ }^{1}$ Regis Chantalat, ${ }^{2}$ \\ Mohamad Hajj, ${ }^{2}$ Eric Arnaud, ${ }^{1}$ Bernard Jecko, ${ }^{1}$ Thierry Monediere, ${ }^{1}$ \\ Christelle Boustie, ${ }^{3}$ and Baptiste Palacin ${ }^{3}$
}

${ }^{1}$ XLIM-CNRS UMR 6172, Faculté des Sciences et Techniques, Université de Limoges, 87060 Limoges, France
${ }^{2}$ CISTEME, ESTER Technopole, 87069 Limoges, France
${ }^{3}$ Service Télécommunications et Navigation, Centre National d'Etudes Spatiales (CNES), 18 Avenue Edouard Belin,
31401 Toulouse Cedex 9, France

Correspondence should be addressed to Moustapha Salah Toubet, moustapha.salah-toubet@xlim.fr

Received 9 February 2012; Accepted 8 May 2012

Academic Editor: Z. Chen

Copyright (C 2012 Moustapha Salah Toubet et al. This is an open access article distributed under the Creative Commons Attribution License, which permits unrestricted use, distribution, and reproduction in any medium, provided the original work is properly cited.

This paper describes the design of a compact and wide angular circularly polarized low-profile EBG antenna. Except at $3.7 \mathrm{GHz}$ and for $\theta$ lower than $-25^{\circ}$ in the plane $\Phi$ equals to $0^{\circ}$, the modelized structure provides an axial ratio lower than $3 \mathrm{~dB}$, over a wide angular aperture of $60^{\circ}$ and over a bandwidth of $5.3 \%([3.7 \mathrm{GHz}-3.9 \mathrm{GHz}])$. It has a very low height of $11.9 \mathrm{~mm}(\lambda / 7$ at $3.8 \mathrm{GHz})$. A prototype has been manufactured, and the measured performances, considering the tolerance of the measurement base $( \pm 0.5 \mathrm{~dB})$, are quite similar to the simulated ones.

\section{Introduction}

Today, several techniques implemented on satellite communication systems (such as multiinput multioutput) require compact antennas with good circular polarization.

A compact antenna generally used to generate a circular polarization is the printed antenna (patch antenna) [1]. But, its main disadvantage is its low gain.

A solution to increase the patch gain while keeping a compact structure is to consider a low-profile EBG antenna.

Indeed, this solution can provide a directivity of $10 \mathrm{dBi}$ [2], which is equivalent to the one obtained with several patch antennas, and presents an ultralow cavity height below $\lambda / 10[2]$.

This subwavelength cavity concept has been widely used in many publications for linear polarization applications [29].

In this paper, we propose a wide angular $\left(60^{\circ}\right)$ circularly polarized low-profile EBG antenna for spatial communications.
According to the CNES (Centre National d'Etudes Spatiales) specifications, the designed antenna must meet several requirements (Table 1 ).

The desired dimensions are $60 \mathrm{~mm} * 70 \mathrm{~mm} * 11.9 \mathrm{~mm}$ (length $*$ width $*$ height). The circular polarization considered is the left one. An axial ratio lower than $3 \mathrm{~dB}$, over the angular aperture $\theta\left(60^{\circ}\right)$, and over a frequency bandwidth of $200 \mathrm{MHz}(5.3 \%)$ is desired. Concerning the gain, it must be higher than $5 \mathrm{~dB}$ over the desired angular aperture with a maximum in the boresight direction ( $\theta$ equals to $\left.0^{\circ}\right)$ of $8.5 \mathrm{~dB}$.

Before presenting the simulated and measured performances of the final structure, it is initially necessary to explain the low-profile EBG antenna design.

\section{Design of the Low-Profile EBG Antenna}

The designed antenna (Figure 1(a)) satisfies the size specifications. 
TABle 1: Antenna specifications.

\begin{tabular}{ll}
\hline Dimensions & $\begin{array}{l}\text { Length: } 60 \mathrm{~mm} \text {, width: } 70 \mathrm{~mm} \text {, and } \\
\text { height: } 11.9 \mathrm{~mm}(\lambda / 7 \text { at } 3.8 \mathrm{GHz})\end{array}$ \\
Frequency & $3.7 \mathrm{GHz}-3.9 \mathrm{GHz}$ \\
Polarization & Left circular polarization \\
Axial ratio & $<3 \mathrm{~dB}$ \\
Angular aperture & $\theta\left[-30^{\circ}, 30^{\circ}\right]$ \\
Boresight Gain & $8.5 \mathrm{~dB}$ \\
Gain at $\pm 30^{\circ}$ & $>5 \mathrm{~dB}$ \\
\hline
\end{tabular}

The EBG cavity (Figure 1(b)) is formed between the ground plane and the FSS placed above it. The FSS is composed by a centered and periodic assembly of square patches $\left(9 \mathrm{~mm} * 9 \mathrm{~mm}\left[\begin{array}{lllll}0 & x & * & 0 & y\end{array}\right]\right)$ (Figure $\left.1(\mathrm{a})\right)$. In order to facilitate the manufacturing of the antenna, the FSS is directly printed at the bottom of a FSS substrate.

The feed system considered, consists of a patch (Figure 2(a)) fed by four feed points that are connected to the four outputs of a distribution circuit ( 1 input and 4 outputs) located under the ground plane (Figure 2(b)). This distribution circuit (Figure 2(b)) is optimized to provide the ideal weights $P_{i}(1)$ at $3.8 \mathrm{GHz}$ for the generation of the left circular polarization

$$
\begin{array}{cc}
P_{1}=\left(0.5,0^{\circ}\right), & P_{2}=\left(0.5,90^{\circ}\right) \\
P_{3}=\left(0.5,180^{\circ}\right), & P_{4}=\left(0.5,270^{\circ}\right) .
\end{array}
$$

The connection between the patch and the distribution circuit is made using four $50 \mathrm{ohm}$ SMA cables (Figure 1(b)).

The design of this antenna which must satisfy at very restrictive specifications (Table 1 ) has been difficult to obtain. The main difficulty encountered has been the coupling [10] between the four feed points of the antenna (Figure 2(a)).

\section{Coupling between the Feed Points of the Antenna}

3.1. Explanation. The main difficulty encountered is the strong coupling between the feed points of the antenna located in the same axis $(\{1,3\}$ and $\{2,4\})$ (Figure $2(a)$ ), that can be observed in linear polarization (without the distribution circuit presence). Indeed, when the feed point 1 is fed and the others loaded on 50 ohms (Figure 3), almost half of the energy is captured by the feed point located in the same axis, namely, 3 (Figure 2(a)). While the coupling levels of the feed points not located in the same axis (2 and 4) are negligible (Figure 3 ). The same observations can be made when the other feed points of the antenna are successively fed. When the antenna will be connected to the distribution circuit (Figure 4 ), a reflected field $\left(F_{i}\right)$ at each feed point $i$ of the antenna, due to the coupling [10], will change the ideal weights $\left(P_{i}\right)(1)$ provided by the distribution circuit. Then, the axial ratio will be altered because the weights at the feed points of the antenna are different than the ideal ones $P_{i}(1)$

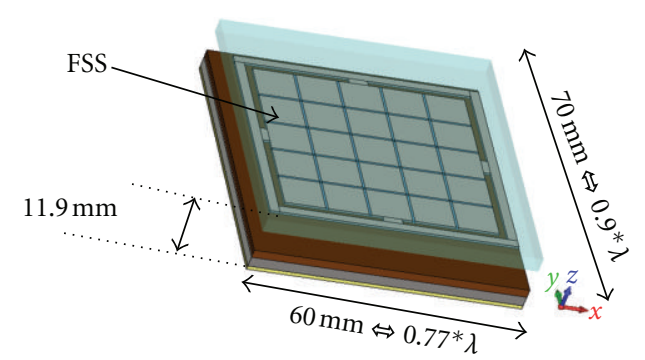

(a)

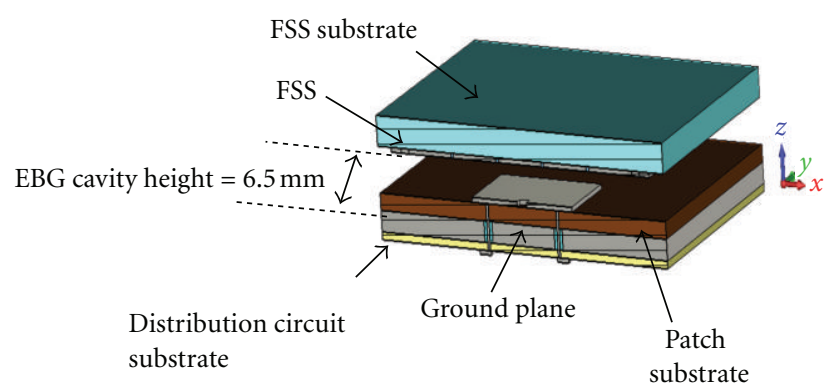

(b)

FIGURE 1: Top (a) and inside (b) views of the designed low-profile EBG antenna.

needed for the generation of a good left circular polarization (Figure 4).

3.2. Solution. The solution has been to reduce the reflected field $\left(F_{i}\right)(2)$ at each of the four feed points of the network [10]

$$
F_{i}=\sum_{j=1}^{4} S_{i j} * P_{j},
$$

where $P_{j}(1)$ and $S_{i j}$ are; respectively, the ideal weights and the $S$ parameters.

Equation (2) can be simplified by neglecting the coupling $S$ parameters of the feed points which are not located at the same axis than the fed one (Figure 3 ). The simplified equation (3) shows that each $F_{x}$ parameter depends on the reflection parameter $\left(S_{x x}\right)$ associated to the fed access $x$ and the coupling parameter $\left(S_{x y}\right)$ of the access $y$ located in the same axis as $x$

$$
F_{x}=\left(S_{x x} * P_{x}\right)+\left(S_{x y} * P_{y}\right) .
$$

To reduce the reflected field $\left(F_{x}\right)$ at each feed point $x$, and knowing that if we consider the ideal weights affected by the distribution circuit $\left(P_{x}\right.$ equals to $\left.-P_{y}\right)$, it is necessary that the $S$ parameters associated to the pairs of feed point $\{x, y\}$, namely, $S_{x x}$ and $S_{x y}$ be identical in modulus and phase:

$$
S_{x x}=S_{x y}
$$

To satisfy (4), the solution has been to dismatch each feed point $x$ of the antenna in order to have the reflection parameter $\left(S_{x x}\right)$ equal to the associated coupling parameter $\left(S_{x y}\right)$. 


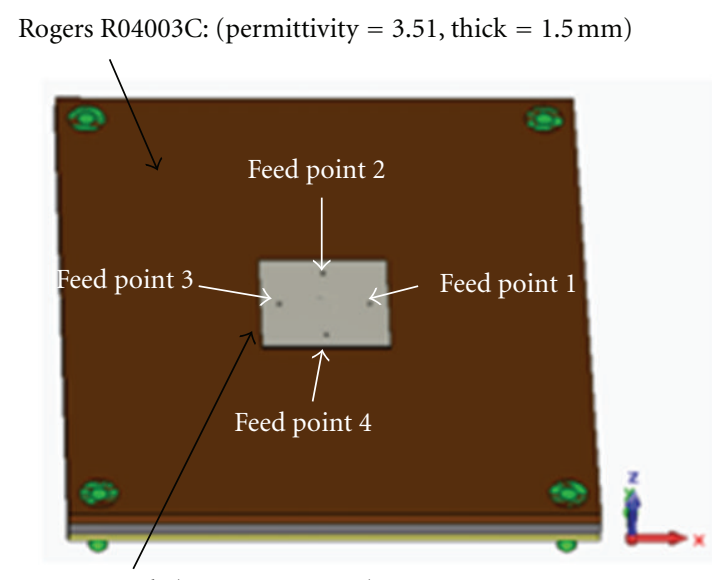

Square patch $(20 \mathrm{~mm} * 20 \mathrm{~mm})$

(a) Patch with four feed points

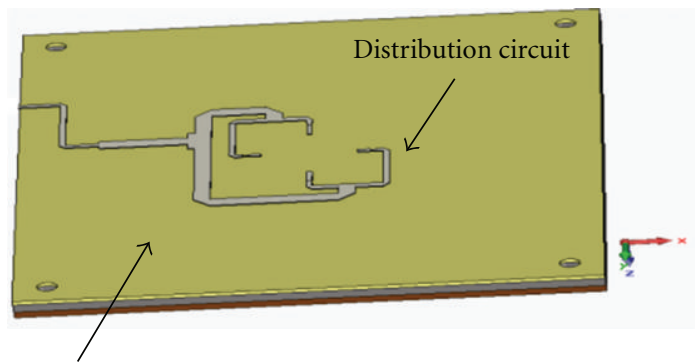

Rogers R04003C: (permittivity $=3.64$, thick $=0.4 \mathrm{~mm}$ )

(b) Distribution circuit located under the ground plane

FIgURE 2: Feed system of the designed antenna.

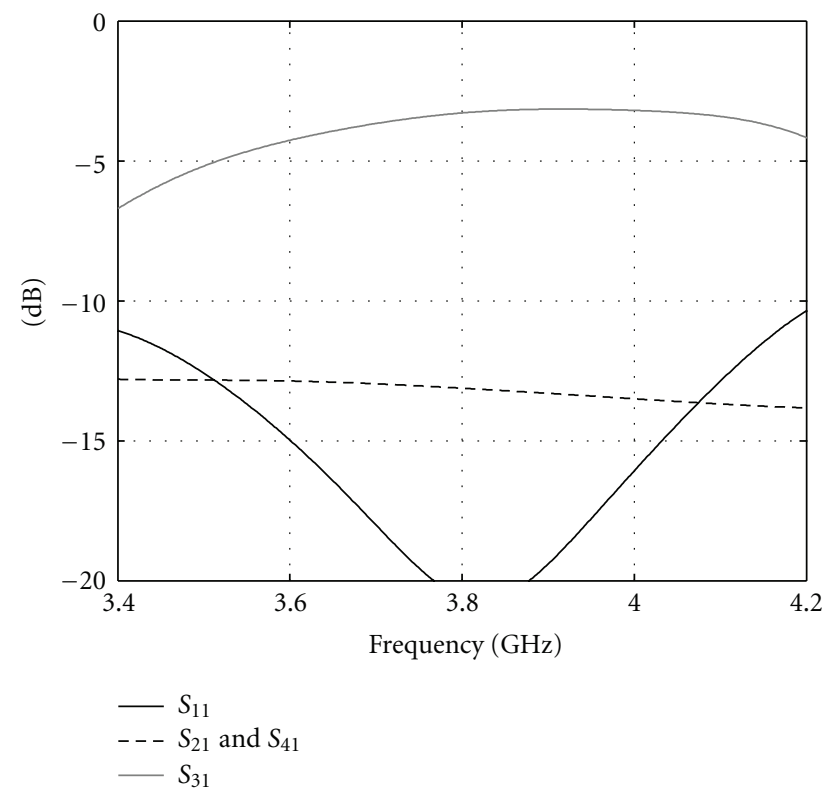

FIGURE 3: Coupling between the feed points of the low-profile EBG antenna without the distribution circuit when the feed point 1 is fed and the others loaded on $50 \mathrm{ohm}$.

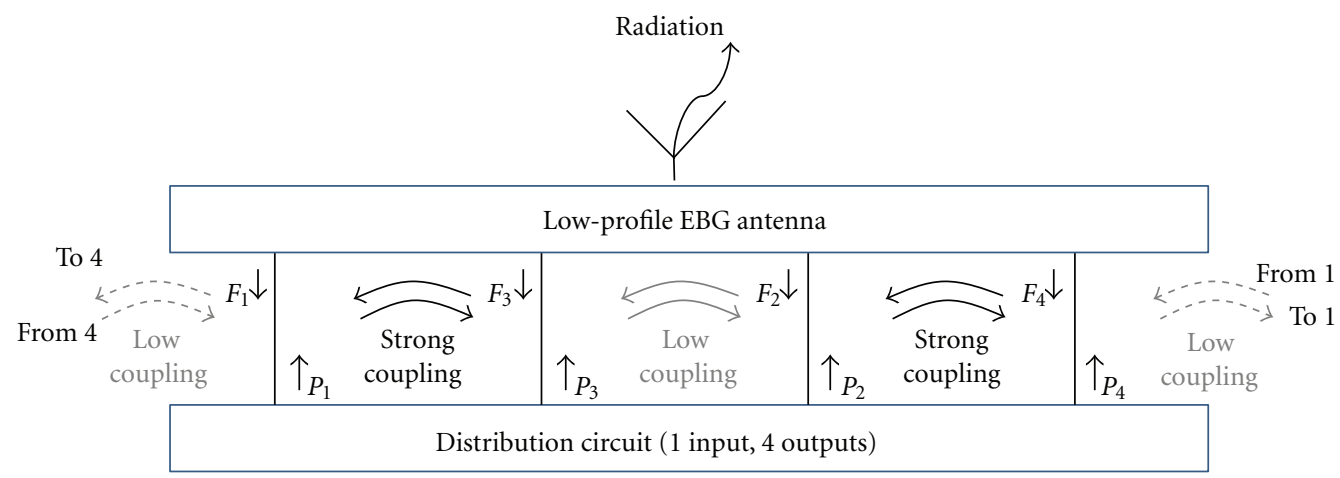

FIGURE 4: Illustration of the reflected field $\left(F_{i}\right)$ at each feed point $i$ of the antenna when it is connected to the distribution circuit. 


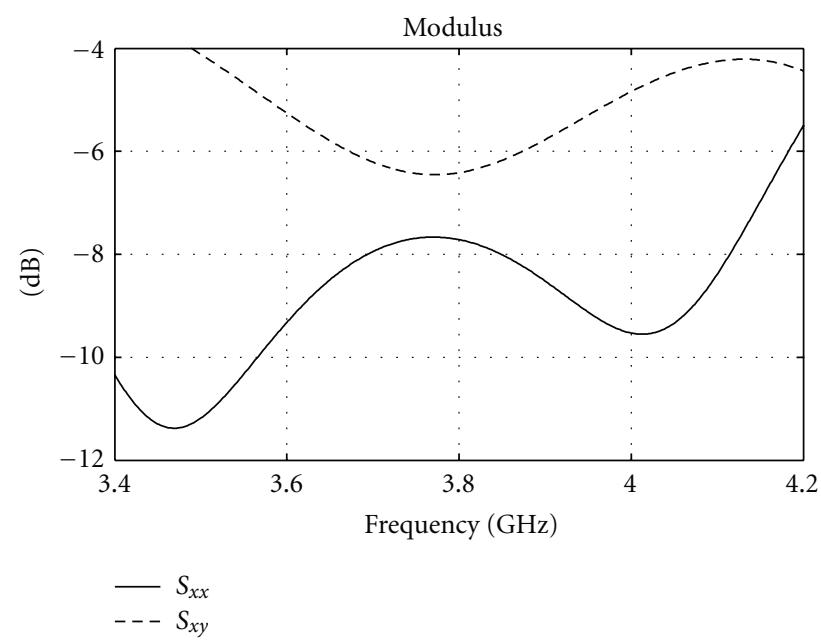

(a)

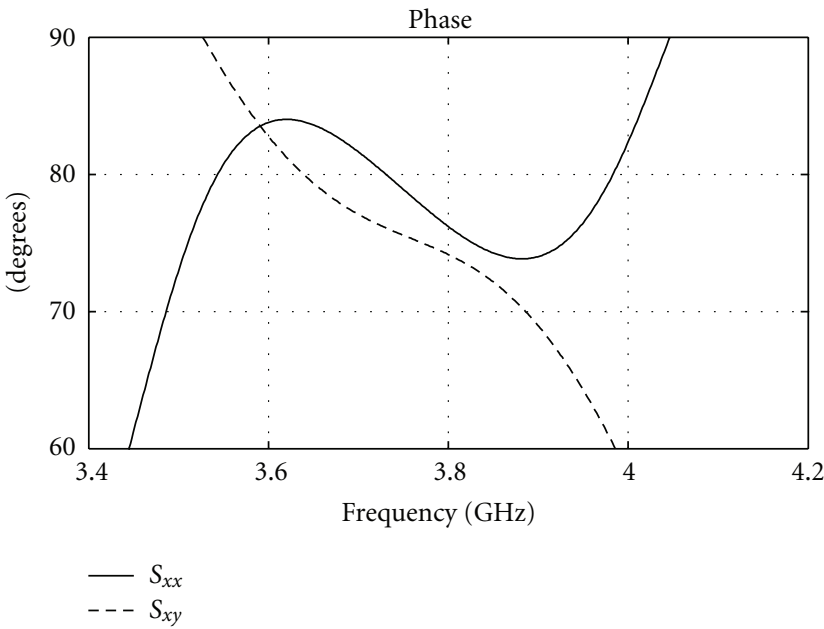

(b)

FIGURE 5: Optimized $S$ parameters $\left(S_{x x}\right.$ and $\left.S_{x y}\right)$ in simulation.

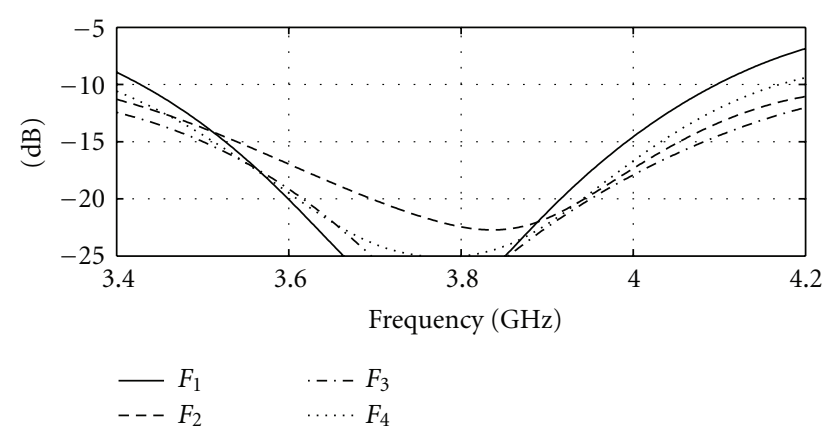

FIGURE 6: Simulated reflected field at each feed point of the antenna.

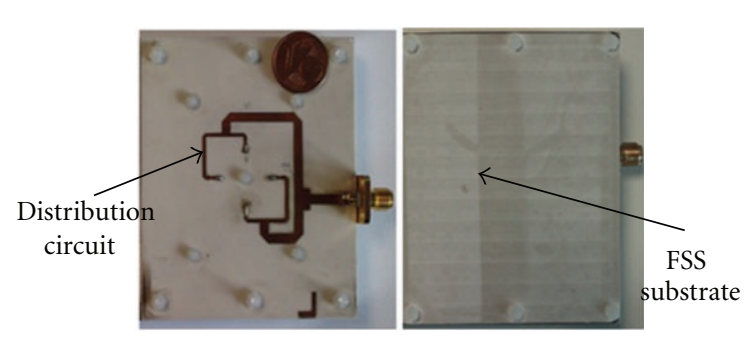

Figure 7: Bottom (left) and top (right) views of the manufactured prototype.

In practice as the distribution circuit presents a dispersion as a function of the frequency, the weight $P_{x}$ does not strictly equal to $-P_{y}$ on the entire $200 \mathrm{MHz}$ bandwidth desired. It is therefore not necessary that the $S_{x x}$ parameter strictly equals to $S_{x y}$. So considering the dispersion of the distribution circuit, we have optimized the antenna using CST software in order to obtain the adequate $S$ parameters $\left(S_{x x}\right.$ and $\left.S_{x y}\right)$ (Figure 5) for reducing the reflected field at each feed point of the antenna on the entire $200 \mathrm{MHz}$ bandwidth desired (Figure 6).

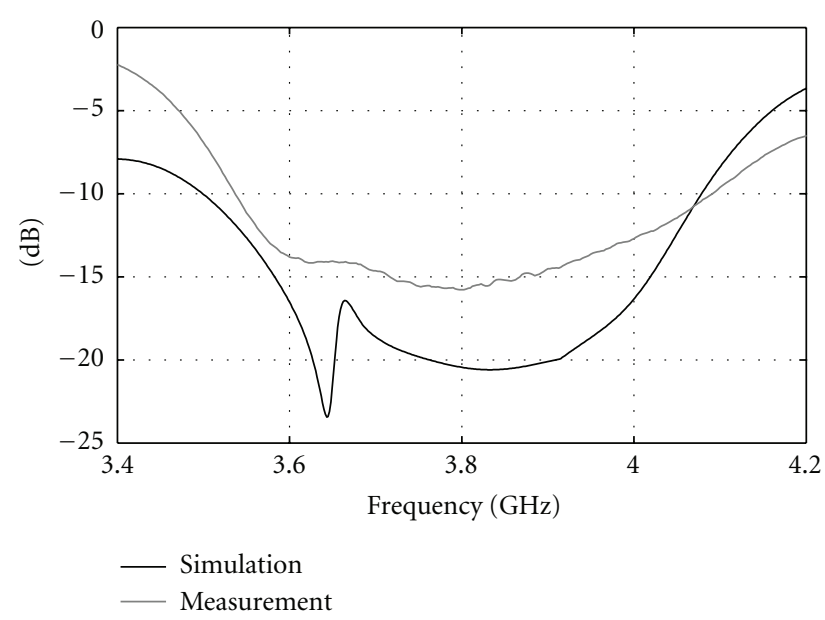

FIGURE 8: Simulated and measured return losses.

Now that the reflected field at each feed point of the antenna has been reduced, it is necessary to present the simulated results and compare them with the measured ones.

\section{Manufactured Prototype and Results}

4.1. Manufactured Prototype. The prototype (Figure 7) has been easy to manufacture it because the patch, the distribution circuit, and the FSS have been made by etching with an LPKF-S100 device.

4.2. Comparison between the Simulated and Measured Results. The simulated and measured return losses of the antenna obtained with the distribution circuit are quite similar (Figure 8). The designed structure is matched to $-10 \mathrm{~dB}$ in simulation over a bandwidth of $15.3 \%([3.5-4.08] \mathrm{GHz})$. This bandwidth is in measurement about $15.2 \%$ ([3.524.1] $\mathrm{GHz}$ ). If we now consider the frequency bandwidth defined in the specifications $([3.7-3.9] \mathrm{GHz})$, the simulated 

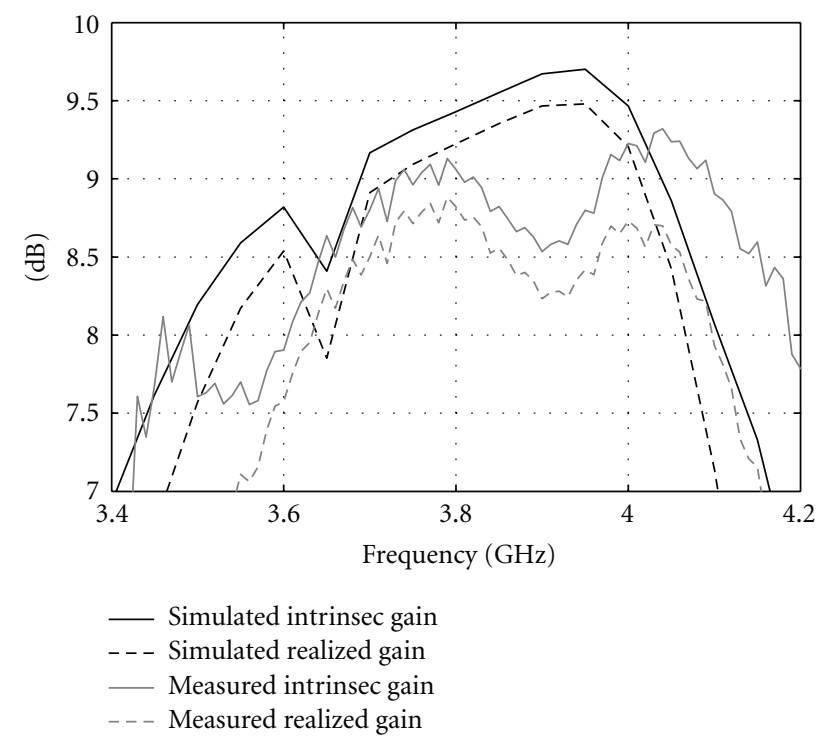

FIGURE 9: Comparison between simulated and measured radiation results.

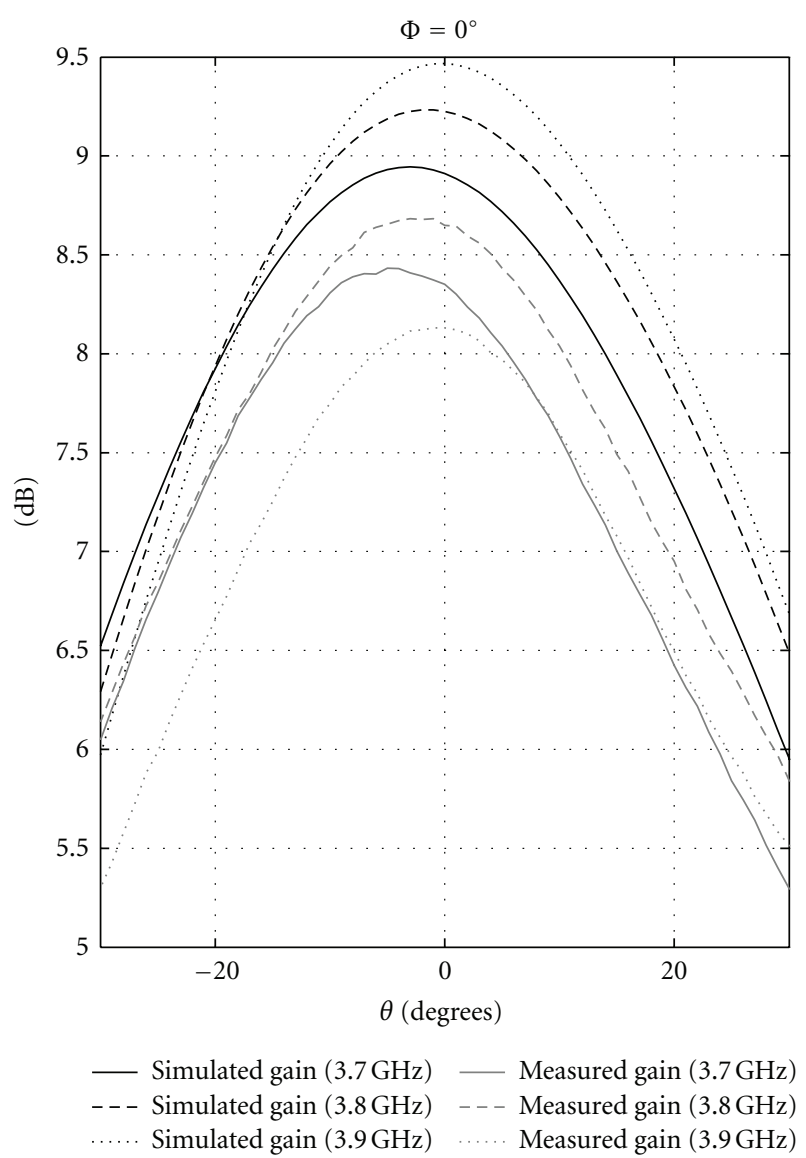

(a)

Figure 10: Continued. 


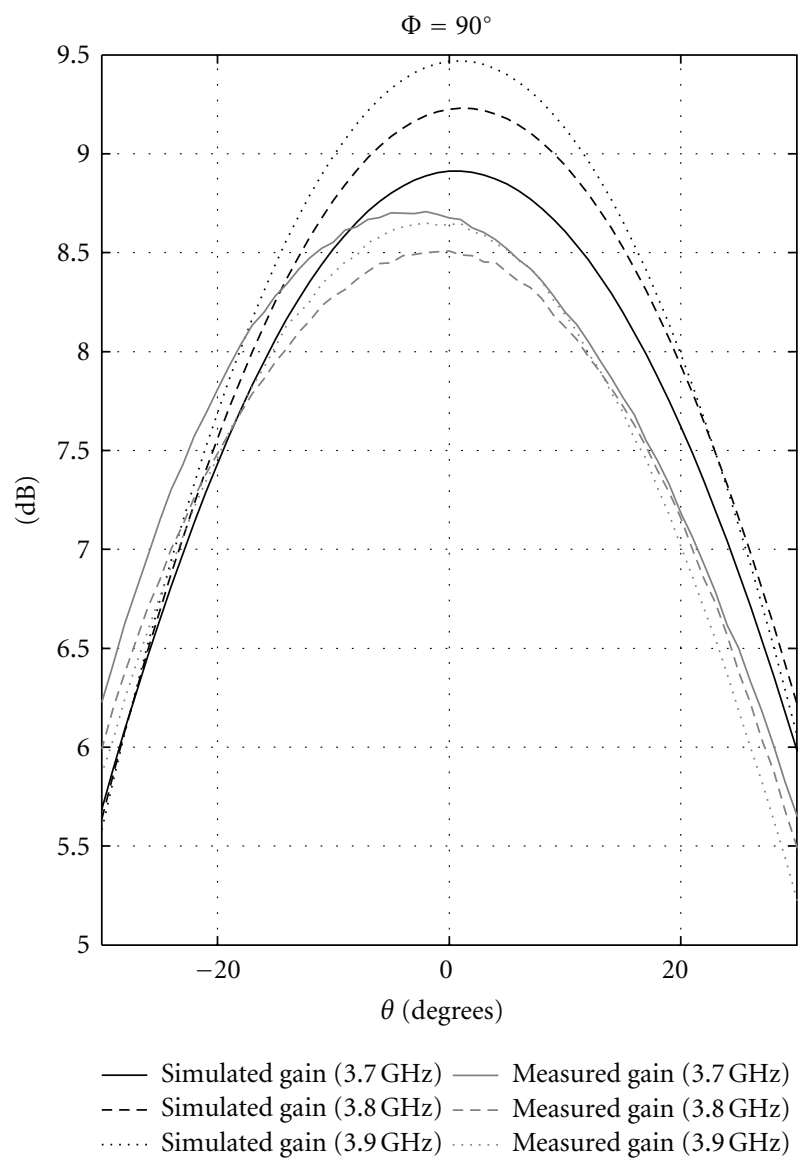

(b)

Figure 10: Simulated and measured realized gain obtained over the angular aperture in the two principal $\Phi$ planes $\left(0^{\circ}\right.$ at left and $90^{\circ}$ at right).

return loss is lower than $-18 \mathrm{~dB}$, while the measured one is below $-14 \mathrm{~dB}$. Although the measurement may be less satisfactory than the simulation, we can still conclude that the achieved prototype is consistent with the specification of $-10 \mathrm{~dB}$.

In terms of radiation, there is a maximum difference between the simulated realized gain in the left circular polarization and the simulated intrinsic gain (Figure 9) of $0.6 \mathrm{~dB}$, due to the return loss (Figure 8). Moreover this difference, considering the tolerance of the measurement base $( \pm 0.5 \mathrm{~dB})$ is also observed between the measured intrinsic gain and the realized one over the bandwidth where the antenna is matched in measurement [3.52-4.1] GHz. In terms of levels, the simulated realized gain at the boresight direction ( $\theta$ equals to $0^{\circ}$ ) higher than $9 \mathrm{~dB}$ over the band [3.7-3.9] GHz satisfies the specifications of $8.5 \mathrm{~dB}$ in this direction. Regarding the measured one, a value higher than $8.2 \mathrm{~dB}$ over the desired bandwidth is obtained. The realized gain dip at $3.9 \mathrm{GHz}$ in the manufactured antenna, less than $0.5 \mathrm{~dB}$ compared to the maximum value at $3.75 \mathrm{GHz}$, can be explained by the tolerance of the measurement base
$( \pm 0.5 \mathrm{~dB})$. This latter explains also the fact that the measured realized gain in the two $\Phi$ planes $\left(0^{\circ}\right.$ and $\left.90^{\circ}\right)$ are not equal at the boresight direction ( $\theta$ equals to $0^{\circ}$ ) (Figure 10$)$.

Finally, the measured gain, higher than $5.2 \mathrm{~dB}$ over the angular aperture with a maximum at the boresight direction $\left(\theta\right.$ equals to $\left.0^{\circ}\right)$ greater than $8.2 \mathrm{~dB}$, are close to the specifications.

Figure 11 illustrates the simulated and measured axial ratio in two $\Phi$ planes $\left(0^{\circ}\right.$ and $\left.90^{\circ}\right)$ over an angular aperture of $60^{\circ}$ and for 3 frequencies of the working band. The most favorable case is at $3.8 \mathrm{GHz}$, because it is at this frequency that we have optimized the antenna and in particular the distribution circuit. We can also notice that the variation of the axial ratio is not symmetrical because the structure is rectangular (Figure 1(a)). Moreover, it is not necessarily minimal in the boresight due to the fact that the structure is optimized to generate an axial ratio less than $3 \mathrm{~dB}$ over a wide angular range $\left[-30^{\circ}, 30^{\circ}\right]$, and not in a fixed direction. Apart from $3.7 \mathrm{GHz}$ and for $\theta$ lower than $-25^{\circ}$ in the plane $\Phi$ equal to $0^{\circ}$, the simulated axial ratio is lower than the specification of $3 \mathrm{~dB}$ in the two $\Phi$ planes $\left(0^{\circ}\right.$ and $\left.90^{\circ}\right)$, on 


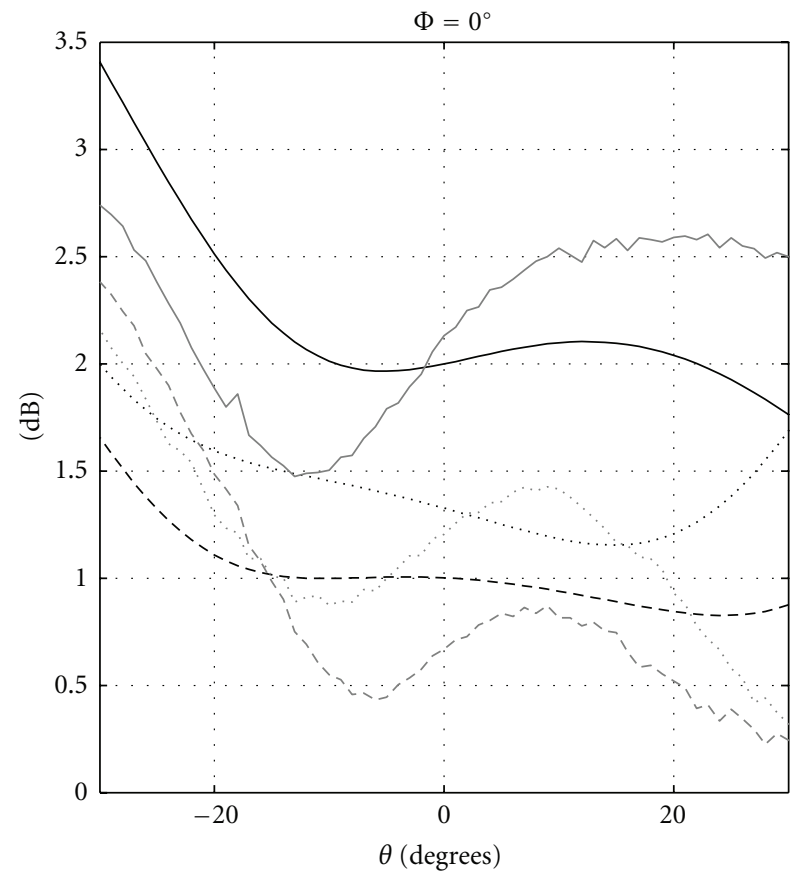

$\begin{array}{ll}\text { - Simulated AR }(3.7 \mathrm{GHz}) & - \text { Measured AR }(3.7 \mathrm{GHz}) \\ \text { - - - Simulated AR }(3.8 \mathrm{GHz}) & --- \text { Measured AR }(3.8 \mathrm{GHz}) \\ \text {.... Simulated AR }(3.9 \mathrm{GHz}) & \text { …. Measured AR }(3.9 \mathrm{GHz})\end{array}$

(a)

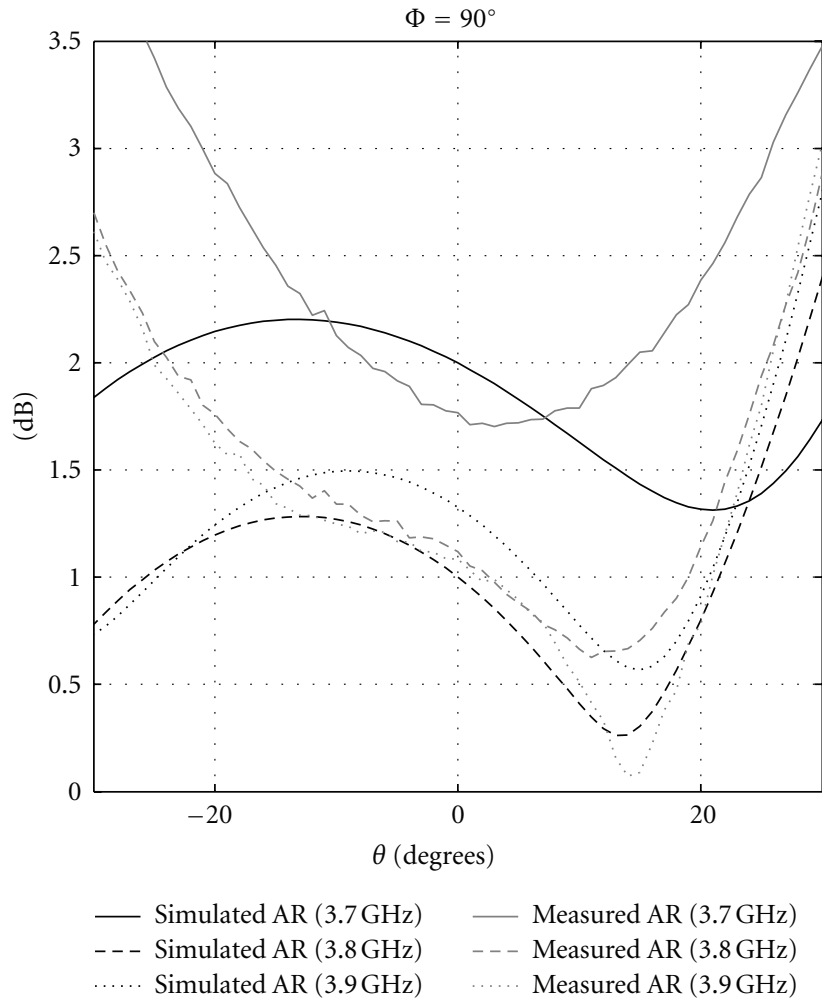

(b)

FIGURE 11: Simulated and measured axial ratio (AR) obtained over the angular aperture in the two principal $\Phi$ planes $\left(0^{\circ}\right.$ at left and $90^{\circ}$ at right).

the entire bandwidth and over all the angular aperture of $60^{\circ}$ (Figure 11). Concerning the measured one, the specifications (angular aperture, axial ratio level and bandwidth) are also satisfied except at $3.7 \mathrm{GHz}$ for $\theta$ lower than $-20^{\circ}$ and greater than $25^{\circ}$ in the plane $\Phi$ equals to $90^{\circ}$. Aside from the special cases defined previously (at $3.7 \mathrm{GHz}$ ), it is possible to conclude that the simulated and the measured axial ratio satisfy the specifications.

It should be also noted that as for the measured realized gain, the measured axial ratio in the two $\Phi$ planes $\left(0^{\circ}\right.$ and $\left.90^{\circ}\right)$ at the boresight direction ( $\theta$ equals to $\left.0^{\circ}\right)$, are not equal due to the tolerance of the measurement base $( \pm 0.5 \mathrm{~dB})$.

\section{Conclusion}

In this paper, the design of a wide angular circularly polarized low-profile EBG antenna for spatial communications has been presented. The conception of this antenna which must satisfy at very restrictive specifications in terms of axial ratio level $(3 \mathrm{~dB})$, angular aperture $\left(60^{\circ}\right)$, and frequency bandwidth ([3.7-3.9] GHz) has been difficult to obtain. Indeed, the coupling between the feed points of the antenna induces reflected field which modify the ideal weights provided by the distribution circuit, and alter the axial ratio. The solution has been to reduce the reflected field at each feed point of the network on the entire bandwidth.
Apart from special cases at $3.7 \mathrm{GHz}$, the designed antenna presents a very low simulated axial ratio $(3 \mathrm{~dB})$, over the wide angular aperture and the frequency bandwidth desired. Considering the tolerance of the measurement base $( \pm 0.5 \mathrm{~dB})$, the manufactured prototype, as expected, provides performances quite similar to the simulated ones.

\section{References}

[1] G. Kumar and K. P. Ray, in Broadband Microstrip Antennas, Broadband Circularly Polarized MSAs, pp. 309-356, Artech House, 2003.

[2] R. Chantalat, L. Moustafa, M. Thevenot, T. Monédière, and B. Jecko, "Low profile EBG resonator antennas," International Journal of Antennas and Propagation, vol. 2009, Article ID 394801, 7 pages, 2009.

[3] S. Wang, A. P. Feresidis, G. Goussetis, and J. C. Vardaxoglou, "High-gain subwavelength resonant cavity antennas based on metamaterial ground planes," IEE Proceedings, vol. 153, no. 1, pp. 1-6, 2006.

[4] Y. Ge, K. P. Esselle, and Y. Hao, "Design of low-profile highgain EBG resonator antennas using a genetic algorithm," IEEE Antennas and Wireless Propagation Letters, vol. 6, pp. 480-483, 2007.

[5] A. P. Feresidis, G. Goussetis, S. Wang, and J. C. Vardaxoglou, "Artificial magnetic conductor surfaces and their application to low-profile high-gain planar antennas," IEEE Transactions on Antennas and Propagation, vol. 53, no. 1 I, pp. 209-215, 2005. 
[6] J. C. Vardaxoglou, A. P. Feresidis, and G. Goussetis, "Recent advances on EBG and AMC surfaces with applications in terminal and high gain antennas," in Proceedings of the 7th International Conference on Telecommunications in Moderm Satellite, Cable and Broadcasting Services (TELSIKS '05), pp. 3-6, September 2005.

[7] D. Sievenpiper, L. Zhang, R. F. Jimenez Broas, N. G. Alexöpolous, and E. Yablonovitch, "High-impedance electromagnetic surfaces with a forbidden frequency band," IEEE Transactions on Microwave Theory and Techniques, vol. 47, no. 11, pp. 2059-2074, 1999.

[8] L. Zhou, H. Li, Y. Qin, Z. Wei, and C. T. Chan, "Directive emissions from subwavelength metamaterial-based cavities," Applied Physics Letters, vol. 86, no. 10, Article ID 101101, pp. $1-3,2005$.

[9] M. S. Toubet, R. Chantalat, M. Thévenot, T. Monédière, and B. Jecko, "Conception of a low-profile and high-gain EBG resonator antenna with wide bandwidth," in Proceedings of the International Workshop on Antenna Technology: Small Antennas, Innovative Structures and Materials (iWAT '10), March 2010.

[10] H. Steyskal and J. S. Herd, "Mutual coupling compensation in small array antennas," IEEE Transactions on Antennas and Propagation, vol. 38, no. 12, pp. 1971-1975, 1990. 

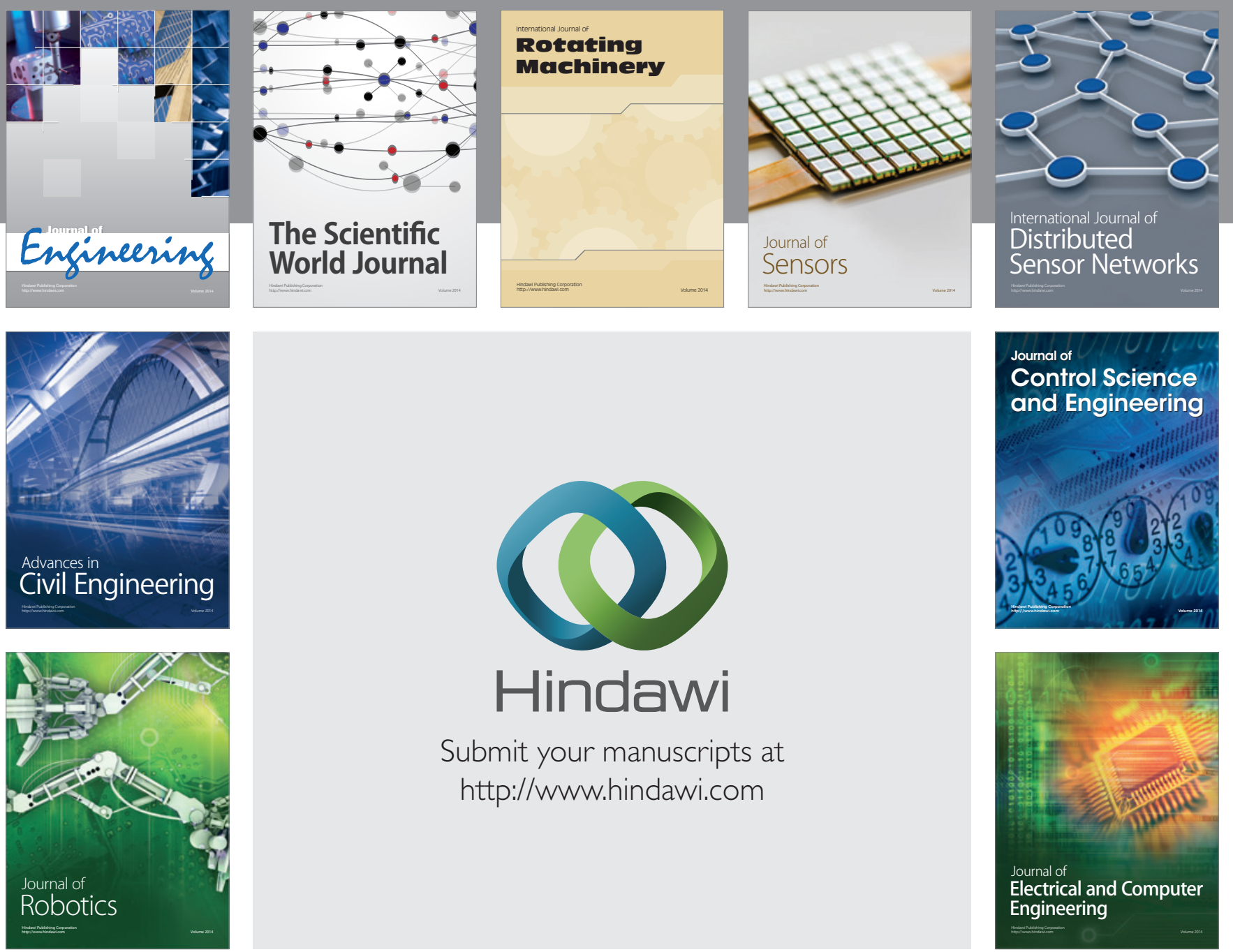

Submit your manuscripts at

http://www.hindawi.com
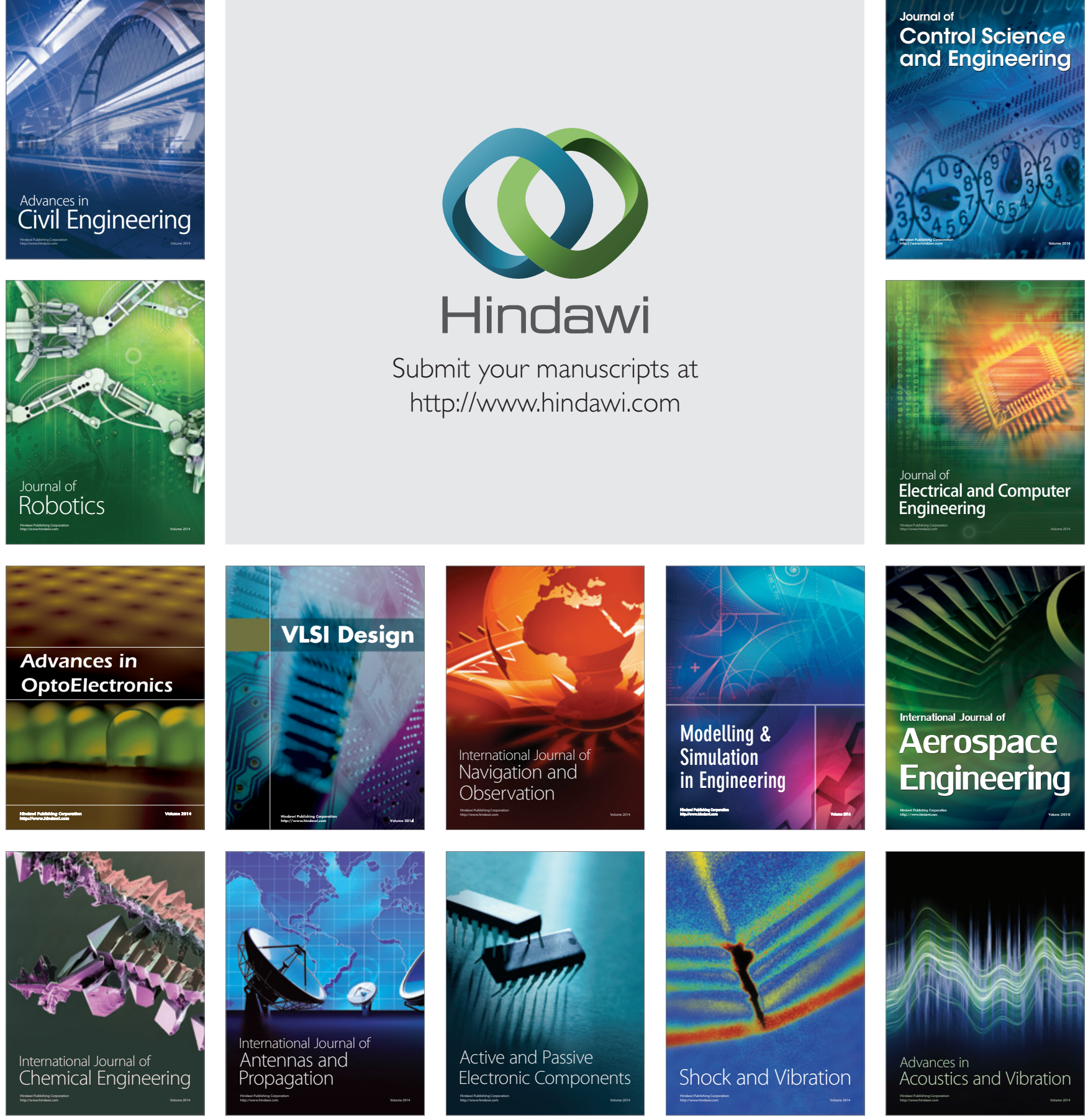